\title{
The COVID-19 Pandemic and Older Adults: Institutionalised Ageism or Pragmatic Policy?
}

\author{
Sarah Harper ${ }^{1}$
}

Accepted: 27 November 2020 / Published online: 12 January 2021

(C) The Author(s), under exclusive licence to Springer Nature B.V. part of Springer Nature 2021

The Covid pandemic has produced a plethora of editorials and commentaries by professional bodies on the specific impact of the SARS-CoV-2 virus and resultant disease COVID-19 on older adults. Threading throughout these is a fundamental framing of the discourse around ageism, age discrimination and the use of chronological age as a homogeneous determinant of societies' acceptable response to the challenge of the vulnerability of older people to the disease.

Perhaps most direct was an early position statement by the British Society of Gerontology (BSG). BSG is a learned society representing those from social science and related research, describing themselves as providing a multidisciplinary forum for researchers and other individuals interested in the situations of older people, and in how knowledge about ageing and later life can be enhanced and improved. Their statement objected to any policy which differentiates the population by application of an arbitrary chronological age in restricting people's rights and freedoms.

"We urge the Government to reject the formulation and implementation of policy based on the simple application of chronological age. We also call on government and media organisations to be cautious in their use of language." (BSG 2020)

Directly referring to the pandemic they continued

Ageism - the stereotyping, prejudice, and discrimination against people on the basis of their age - has detrimental consequences for societies and individuals. We reject firmly the ageist and stereotypical assumptions that underlie public and policy pronouncements that rely solely on the application of chronological age....using age alone as a criterion for decision making is fundamentally wrong"(BSG 2020)

Sarah Harper

sarah.harper@ageing.ox.ac.uk

1 Oxford Institute of Population Ageing, University of Oxford, Oxford, UK 
Akinola (2020) writing for the World Economic Forum similarly stated that

".. even before the pandemic, reports showed that many older adults were already more socially isolated and experienced more loneliness than the rest of the population. Coronavirus containment measures, including confinement measures, physical distancing and restrictions on movement and social gatherings, increased the risk for social isolation and loneliness."

Similar views were espoused by the Editorial of the Journal of Clinical Nursing

"Over the course of the pandemic, we have seen evidence of openly ageist discourses, which we argue, complicates the experiences of living through COVID-19 for older people”. (Brooke and Jackson 2020)

The American Psychology Association went further suggesting that ageism was actually translating into worse healthcare for older age groups.

"Negative stereotyping, prejudice, and discrimination toward older adults during the pandemic (including triaging, inadequate protections in care facilities and the larger community) can translate into worse health care, and increased, tragic loss of older adults" (Monohan et al. 2020)

Adding that in addition ageism

"negatively affects older adults' mental health as they face being devalued, viewed as a burden, and discriminated against. Ultimately, ageism influences how all age groups view their own aging and older adults." (Monohan et al. 2020)

Reflecting on the situation in LMICs, HelpAge International warned that separating generations may worsen intergenerational-tensions and ageist attitudes, and prevent older people from playing their part, in solidarity with younger generations. The intergenerational aspect of this ageism is also emphasised by the BSG stressing that

"It is essential that we continue to foster generational and societal cohesion during the course of the pandemic. Only by bringing the generations together in this time of crisis can we ensure that the least damage is done" (BSG 2020)

The Irish Gerontology Society added a new dimension around rationing of care during the pandemic. 
Treatment for COVID-19, and other forms of resource allocation associated with this crisis, must be based on need. It is concerning that we are hearing reports from other countries that when it comes to decisions around available treatments - be it home care supports, medicines or ventilation - that age alone was being used as a criteria (O'Shea 2020).

Resource allocation must be based on need not age.

Morbidity, cumulative chronic illnesses and pre-acute illness physical condition (or Frailty) should sufficiently indicate or predict likelihood of a good outcome and surviving an illness. An arbitrary age cut off takes none of these into account. Prioritizing younger, healthier patients with a higher chance of recovery, as has been suggested in other countries, is "ageist" in the extreme. Indeed the concept of "life years saved", could be considered to be similarly "ageist" and if extended could include many people, young and old, perceived as marginalized groups in our society.

One of these key issues highlighted was the view that older adults are a homogeneous group. As the editorial in the Journal of Gerontology highlighted we are seeing in public discourse an increasing portrayal of those over the age of 70 as being all alike with regard to being helpless, frail, and unable to contribute to society (Alayon et al. 2020). Similarly from the World Economic Forum

\begin{abstract}
"Ageism tends to paint all older adults as the same. The reality is that older persons are diverse and have several different identities. They are more than their age". (Akinola 2020)
\end{abstract}

During the pandemic, governments have warned older people that they are at a higher risk of both severe illness and death with COVID-19. Early mortality data, on which much of this advice quickly emerged, indicated rising mortality rates from $1.3 \% 50$ to 59 years, $3.6 \% 60$ to 69 years, $8 \%$ 70-79 years to $14.8 \%$ for those aged over 80 , leading to a general recommendation in many countries that older people should stay at home and avoid social contact. This was despite the fact that there was widespread evidence from our understanding of other later life illness that gender, ethnicity, socioeconomic status and co-morbidities would discriminate between members of these age groups. It became clear as the pandemic proceeded, that certain ethnic groups appeared to have a greater vulnerability to risk, and that socio-economic factors played a key role in vulnerability. The influence of gender was clear. Women have in general a 5 year advantage over men in terms of risk. In addition, existing disease amplifies that risk, so for example, both men and women in their 50s and 60s have around 4 times the average gender weighted risk of dying at that age if they have chronic kidney disease, and 3 to 4 times if they have cardio-vascular disease. However, women at every age have a lower risk, and their overall risk of death, even with a chronic disease, is lower than equivalent men's. In all cases, the risk is made higher if the disease is combined with obesity. 
As the President of the Irish Gerontology Society pointed out

During this pandemic we must be mindful that, like every age group in society, older people are a very heterogeneous group. There are many older people who are very well. We must caution against placing all older people in one large "homogenous" group. Labelling all older individuals as highly vulnerable, frail and passive agents is obviously incorrect and inappropriate (O'Shea 2020).

A similar view was espoused by the BioEthic Forum which accepted that older adults have "increased risks for serious Covid-19 complications" but that "those risks are raised by coexisting conditions, for people of all ages. It is arguably different to use an age range that has verifiable connections to risk versus vague and potentially demeaning labels like "elderly" or "senior" to identify risk. The former is a scientific association; the latter is a social value." (de Medeiros 2020).

The outlier in this debate came from the British Geriatrics Society - the BGS is the membership association for professionals specialising in the healthcare of older people.

We see major differences between different groups in healthy life expectancy at 65. However, even fit older people show poorer immune responses than their younger selves in the face of infection. The speed of the covid-19 pandemic doesn't allow us to assess each person over 70 for individual risk-and the government has made a pragmatic decision. (Oliver 2020)

Oliver agrees that the response by age is not homogeneous and indicates that this was a simple response to an emergency. The question remains that while this may have been an initial pragmatic response, given time to reflect upon the data why would this not change and at what cost is the policy in the long term? Interestingly the BGS has not commented publically further on this, though it has hosted a Blog on its website by Muir Grey on Population Geriatrics which calls for a culture change in the profession.

\section{Institutionalised Ageism or Pragmatic Policy}

The overriding question which arises from this debate is whether the current treatment across the world - of older adults is institutionalised ageism or pragmatic policy. The first fundamental problem in addressing this lies in the tension between individual ageing and population ageing. The lived experiences of a person, and positive effective behaviour towards that person leading to the most favourable outcome for that person, is not replicated at the population level, where a different set of inputs might have a more advantageous population outcome. We might reframe this to suggest there is a tension between the qualitative lived experience of the individual and the quantitative analysis of the population.

Furthermore this is not a simple dichotomy, within are several levels of tension to be resolved. When we come to deconstruct this further the manner in which we do this or the approach we take adds complexity. We confront two major perspectives - 
positivism and interpretivism. That is our assumptions about reality are framed by our ways of exploring this reality. Thus an older person's interpretation of frailty and dependency in late old age emerges from the lived experience of the change in their body, different from the interpretation of the family carer who draws on relational understanding, and from the professional care worker who assesses the apparent needs of the older person drawing on technical training, and different again from the geriatrician who prescribes medication or aids based on medical knowledge. The question is which forms of knowledge should be privileged, and how does this affect the definition of the older adult's situation, and subsequent behaviour towards them and others in similar situations?

In each case some analysis or measurement must be employed, and the dominant approach will tend to be increasingly prioritized as the correct or accepted form of evaluation. Quantification has long been viewed as the dominant scientific approach and seen to impose legitimacy on a course of action. What is quantified gains authority and becomes the governing principal for future developments.

Furthermore is the intersectionality of being (Crenshaw 1989), the multiple existence of various experiences framed by multi-characteristics - our race, sexuality, gender, education etc. Most individuals find themselves at the intersection of multiple dimensions, while our institutions tend to define us by sole characteristics.

In summary, complex experiences are reduced to one simplified reality, which is measured, legitimised, prioritised and ultimately modifies, reorganises and reconstructs the social reality of lived experience itself. The simplified reality becomes the accepted reality by individuals, society and the institutions which comprise it. Indeed it has long been recognised that negative stereotypes of older adults lead to an internalisation of that image by the older person (Levy 2009; Siebert et al. 2020) and institutions follow.

\section{Will the COVID Epidemic Resolve or Worsen this Dichotomy?}

There is some optimism. Lloyd-Sherlock et al. (2020), for example, having previously argued that that global health priority setting is institutionally ageist, proffer the idea that Covid-19 offers an opportunity to prove them wrong. The almost united view of professional bodies writing from different perspectives also produces some hope for change.

Firstly is the contribution which social and behavourial scientists may make. The American Journal of Gerontology argues in its editorial that behavioural scientists have a responsibility to participate in the current public discourse to correct misperceptions, over-generalizations, and ethically questionable suggestions. A similar view is held by both the British and Irish Gerontological societies.

A second avenue of exploration comes from the reinvigorated move towards a possible Human Rights Convention for Older Persons. As the EU Age Platform outlines under Article 2 of the Convention on Human Rights, governments have a legal obligation to take positive steps to protect people whose lives are at risk [HAI 2020; Huchet and Georgantzi 2020]. Governments are currently taking action to protect lives amid the coronavirus pandemic, such as quarantine and isolation policies, which interfere with our other rights. Among those affected is our the right to liberty (Article 5), freedom of assembly (Article 11), and freedom of movement (Article 2). All three of 
these rights can be lawfully interfered with on the grounds of protecting public health and these rights must be balanced with the right to life. However under Article 14 people may not be discriminated against the enjoyment of any of our human rights on grounds defined by our characteristics.

A third course of action is work with policy makers to explore policy making which recognises the inherent tension between individual and population ageing. In the UK context, at least, there has been some room for hope. Several initiatives such as the government's Policy Lab in the Cabinet Office offer a way forward. The Foresight Review of the UK's Ageing Population, for example, combined ethnographic, speculative design and possible futures work to explore with a range of government departments this dichotomy. Similarly, Poverty2Solutions involving grassroots organisations led by people with lived experience of poverty have been working to ensure that the voice of lived experience is taken seriously and can inform policy decisions that have an impact on the lives of people in low-income communities.

The global COVID pandemic has disrupted much of the lives we used to live. As the pandemic subsides we will find ourselves at new junction, one described by many commentators as significant as the end of the Cold War. As O'Shea (2020) writes on behalf of the Irish Gerontology Society, we must not let this crisis undo all the work many before us have done to establish the very strong bond that we have witnessed across the generations. Pragmatic policy making is one thing in a crisis, long term institutionalised ageism is another.

\section{References}

Akinola, S. (2020) COVID-19 has worsened ageism. Here's how to help older adults thrive. Shaping the future of health and healthcare. World Economic Forum https://www.weforum.org/agenda/2020/10/ covid-19-has-worsened-ageism-here-s-how-to-help-older-adults-thrive/.

Alayon, L., et al. (2020). Editorial: Aging in times of the COVID-19 pandemic: Avoiding ageism and fostering intergenerational solidarity. Journal of Gerontology: Psychological Sciences, XX(XX), 1-4. https://doi.org/10.1093/geronb/gbaa051.

Brooke, J. and Jackson, D. (2020). Older people and COVID-19: Isolation, risk and ageism. Editorial Journal of Clinical Nursing https://doi.org/10.1111/jocn.15274.

BSG (2020). Statement from the President and Members of the National Executive Committee of the British Society of Gerontology on COVID-19. https://www.britishgerontology.org/publications/bsg-statementson-covid-19/statement-one. Accessed 27 Nov 2020

Crenshaw, K. (1989). Demarginalizing the intersection of race and sex: A black feminist critique of antidiscrimination doctrine, Feminist Theory and Antiracist Politics University of Chicago Legal Forum Issue 1 Article 8 139-167.

de Medeiros, K. (2020). A Covid-19 side effect: Virulent resurgence of ageism, Hastings Bioethics Forum 14 May 2020.

HAI (2020) Age-based measures coming out of lockdown. Position Statement.

Huchet, E. and Georgantzi, N. (2020) Ageism in the age of Covid-19. Age Platform Europe.

Levy, B. (2009). Stereotype embodiment: A psychosocial approach to aging. Current Directions in Psychological Science, 18(6), 332-336. https://doi.org/10.1111/j.1467-8721.2009.01662.x.

Lloyd-Sherlock, P., et al. (2020). Bearing the brunt of covid-19: Older people in low and middle income countries. BMJ, 368, m1052. https://doi.org/10.1136/bmj.m1052.

Monohan, C., et al. (2020). COVID-19 and ageism: How positive and negative responses impact. Older Adults and Society American Psychologist, 75(7), 887-896 ISSN: 0003-066X. https://doi.org/10.1037/ amp0000699.

O'Shea, D. (2020). Principles in the COVID-WORLD. Irish Gerontological Society. https://www. irishgerontology.com/news/latest-news/principles-covid-world 
Oliver, D. (2020). What the pandemic measures reveal about ageism. BMJ, 369. https://doi.org/10.1136/bmj. m1545.

Siebert, J., Braun, T., \& Wahl, H.-W. (2020). Change in attitudes toward aging: Cognitive complaints matter more than objective performance. Psychology and Aging, 35(3), 357-368. https://doi.org/10.1037/ pag0000451.

Publisher's Note Springer Nature remains neutral with regard to jurisdictional claims in published maps and institutional affiliations. 